\title{
Dosimetric advantages of proton therapy over conventional radiotherapy with photons in young patients and adults with low-grade glioma
}

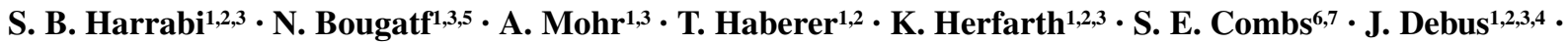 \\ S. Adeberg $1,2,3,4$
}

Received: 6 January 2016 / Accepted: 20 May 2016 / Published online: 30 June 2016 (C) The Author(s) 2016. This article is available at SpringerLink with Open Access.

\begin{abstract}
Background and purpose Low-grade glioma (LGG) is a very common brain tumor in pediatric patients typically associated with a very good prognosis. This prognosis makes it imperative that the risk of long-term treatment-related side effects be kept at an absolute minimum. Proton therapy (PRT) provides a radiation technique that has the potential to further reduce the genesis of radiogenic impairment.

Materials and methods We retrospectively assessed 74 patients with LGG who underwent PRT. Conventional threedimensional photon and PRT plans were generated after contouring structures of neurogenesis, crucial neuronal structures, and areas susceptible to secondary malignancies. Target volume coverage was evaluated using the
\end{abstract}

S. Adeberg, M.D.

sebastian.adeberg@med.uni-heidelberg.de

1 Heidelberg Institute of Radiation Oncology (HIRO), Im Neuenheimer Feld 400, 69120 Heidelberg, Germany

2 Heidelberg Ion-Beam Therapy Center (HIT), Im Neuenheimer Feld 450, 69120 Heidelberg, Germany

3 Dept. of Radiation Oncology, University Hospital Heidelberg, Im Neuenheimer Feld 400, 69120 Heidelberg, Germany

4 Clinical Cooperation Unit Radiation Oncology, German Cancer Research Center (DKFZ), Im Neuenheimer Feld 280, 69120 Heidelberg, Germany

5 Department of Medical Physics in Radiation Oncology, German Cancer Research Center (DKFZ), Im Neuenheimer Feld 280, 69120 Heidelberg, Germany

6 Department of Radiation Sciences (DRS), Institute of Innovative Radiotherapy (iRT), Helmholtz Zentrum München, Ingolstädter Landstraße 1, 85764 Oberschleißheim, Germany

7 Partner Site Munich, Deutsches Konsortium für Translationale Krebsforschung (dktk), Munich, Germany homogeneity index (HI) and inhomogeneity coefficient (IC). Results were compared using the Wilcoxon-signed rank test, with $p<0.05$ being statistically significant.

Results Target volume coverage was comparable for the photon and proton plans. Overall, we could show an essential reduction in maximal, mean, and integral doses in critical neurologic structures, areas of neurogenesis, and structures of neurocognitive function. The study indicated specifically how contralaterally located structures could be spared with PRT.

Conclusion PRT is a highly conformal radiation technique offering superior dosimetric advantages over conventional radiotherapy by allowing significant dose reduction for organs at risk (OAR) that are essential for neurologic function, neurocognition, and quality of life, thus demonstrating the potential of this technique for minimizing long-term sequelae.

Keywords Brain tumors · Children · Neurogenesis · Quality of life · Organs at risk

\section{Dosimetrische Vorteile der Protonentherapie gegenüber der konventionellen Strahlentherapie mit Photonen bei jungen Patienten und Erwachsenen mit niedriggradigem Gliom}

\section{Zusammenfassung}

Hintergrund und Ziel Niedriggradige Gliome (LGG) zählen zu den häufigsten Hirntumoren im Kindesalter und sind üblicherweise mit einer sehr guten Prognose vergesellschaftet. Es gilt daher, das Risiko für therapieassoziierte Spätfolgen so gering wie möglich zu halten. Mit der Protonenbestrahlung steht eine Bestrahlungsmodalität zur Verfügung, mit der das Auftreten radiogener Spätfolgen im Vergleich 
zu konventionellen Bestrahlungstechniken weiter minimiert werden könnte.

Material und Methoden Für diese Studie wurden 74 konsekutive Patienten retrospektiv ausgewertet, die aufgrund eines LGG einer Protonenbestrahlung unterzogen wurden. Ergänzend wurden zunächst auf der Planungscomputertomographie die für neurokognitive Funktionen relevanten Zentren sowie Strukturen der Neurogenese identifiziert und konturiert; anschließend wurden korrelierende konventionelle Photonenpläne berechnet. Die Zielvolumenabdeckung wurde mithilfe des Homogenitätsindex (HI) und des Inhomogenitätskoeffizienten (IC) beurteilt und die Ergebnisse mit dem Wilcoxon-Vorzeichen-Rang-Test verglichen, wobei ein $p$-Wert $<0,05$ als statistisch signifikant gewertet wurde.

Ergebnisse Die Zielvolumenabdeckung war sowohl für Photonen- als auch für Protonenpläne vergleichbar. Insgesamt konnte mit der Protonentherapie nicht nur die Integraldosis des gesunden Gehirngewebes, sondern auch die maximale und mittlere Dosisbelastung der zuvor definierten kritischen Risikoorgane deutlich gesenkt werden. Dies gilt in besonderem Maße für die dem Tumor kontralateral gelegene Hemisphäre.

Schlussfolgerung Die Protonenbestrahlung zeigt eine der konventionellen Radiotherapie mit Photonen in Hinblick auf Risikoorganschonung bei weitem überlegene dosimetrische Verteilung, mit dem großen Potential, radiogene Spätfolgen - wie die Beeinträchtigung neurologischer und neurokognitiver Funktionen und der Lebensqualität - zu minimieren.

Schlüsselwörter Hirntumor · Kinder · Neurogenese · Lebensqualität · Risikoorgane

Low-grade gliomas (LGG) are the most common type of brain tumor in children. Today, the prognosis is very good and pediatric patients are expected to become long-term survivors. It is, therefore, essential to reduce the risk of long-term side effects as much as possible.

Surgery is generally accepted as the first-line treatment if a complete resection can be achieved without major neurologic impairment. However, in many cases, only a partial resection or biopsy can be performed due to an unfavorable localization in proximity to vital structures such as the brainstem, optic system, pituitary, hypothalamus, or other areas of the brain with critical functions. Since the risk for disease progression is significantly higher in cases of subtotal compared to complete resection [1], radiotherapy plays an important role in the treatment of pediatric LGG. Radiotherapy is one of the most effective treatment alternatives, achieving high long-term control rates [2, 3]; although its use is not undisputed. Nevertheless, given the good prognosis, particular attention is paid to reduction of potential treatment-related sequelae. Younger patient age has been attributed with a higher risk of neurocognitive impairment, neurologic deficits, reduced quality of life, and secondary malignancies. The recommended lower age limit for initiation of radiotherapy differs among international protocols: European trials set the threshold at 8 years of age [4], while North American studies advise waiting until the age of 10 [5]. However, adult patients also show a tendency to develop dementia more frequently after cranial irradiation [6], which is known to be related to a significant impairment of the patient's quality of life.

Over time, many technical advances, such as three-dimensional (3D) treatment planning, image guidance, intensity modulation, and particle therapy, have been adopted in daily routine, leading to incremental improvements in terms of conformity. Three-dimensional conformal radiotherapy (3D-CRT) is a widely available radiation technique accepted as standard [7-9]. A multitude of data is available for 3D-CRT, but long-term studies of PRT are still scarce. Along with the commissioning of new proton facilities, the use of PRT is rapidly increasing [10]. Due to its distinct biophysical properties with typically low doses in the beam entrance area and a nearly complete dose deposition in the so-called Bragg-peak, PRT is a highly conformal technique that allows steep dose gradients. As a result, excellent target coverage can be maintained without compromises due to nearby critical OAR because their tolerances are not exceeded. In view of the dosimetric superiority of PRT compared to 3D-CRT, this study was conducted to present in detail the influence on structures that are essential for neurocognitive function, in addition to specific OAR that are responsible for neurologic side effects or impairment of quality of life. In the world of radiation oncology, sparing of the hippocampus and other stem cell niches has become a topic of particular interest $[11,12]$. However, there are several risk factors for the development of neurocognitive dysfunction: in addition to radiotherapy, tumor localization, the extent of resection, and concomitant chemotherapy are recognized risk factors [13]. The authors set out to determine and quantify the superiority of PRT in terms of dose distribution for the abovementioned OAR and, thereby, evaluate the potential benefit with regard to long-term radiogenic sequelae.

\section{Materials and methods}

\section{Patient selection}

A total of 74 patients with histologically proven LGG originally treated at the authors' institution between 2012 and 2014 were retrospectively selected for this comparative study. All patients presented with supratentorial or infraten- 
torial disease. Approximately half of the patients $(n=36$; $48.6 \%$ ) were children or young adults under 30 years of age (Table 1). For treatment planning, patients were fixed using custom-made mask fixation and underwent pretherapeutic computed tomography (CT) and magnetic resonance imaging (MRI). All patients underwent 3D-PRT or intensity-modulated proton therapy (IMPT) with a median dose of $54 \mathrm{~Gy}$ (range 50.4-60 Gy) in 1.8 Gy per fraction (range 1.8-2.0 Gy), with a horizontal beamline using the raster scanning technique [14]. The patient collective encompassed a wide range of histological LGG subgroups among pilocytic astrocytoma $(n=28 ; 37.8 \%)$, fibrillary astrocytoma ( $n=22 ; 29.7 \%)$, and oligodendroglioma $(n=6$; $8.1 \%)$. Median age of patients with pilocytic astrocytoma was 16.2 years (2.0-53.3 years) and this was 36.3 years (5.9-64.2 years) for other LGG.

\section{Contouring and treatment planning}

Contouring was performed on the patients' original treatment planning CT scans and fused with the pretherapeutic MRI using contrast-enhanced T2 fluid-attenuated inversion recovery (FLAIR) imaging. The initial gross tumor volume (GTV) was defined as the hyperintense low-grade tumor mass, surgical resection cavity, and perifocal edema on T2FLAIR. A safety margin of up to $1 \mathrm{~cm}$ was added for the clinical target volume (CTV) to account for microscopic spread. All OAR were contoured using coregistered T1weighted postcontrast MRI on axial views. In the authors' study group, at the time of initial treatment planning and delivery, the additional OAR were not explicitly contoured, monitored, or used as avoidance structures for either treatment technique. Contouring of the initial and additional OAR and the treatment volume definition for photon and particle therapy planning was performed using the Siemens Dosimetrist and Oncologist software (Siemens, Erlangen, Germany). Photon RT and PRT re-planning were performed on the original planning CT datasets and dose recalculation was done using the initial planning parameters. Furthermore, additional crucial cerebral structures for neurogenesis, secondary malignancies, and neuronal functions were contoured retrospectively. To allocate the laterality, we determined the tumor key area regardless of bilateral tumor growth. Ipsilateral (IL) and contralateral (CL) subventricular zones (SVZ) were contoured as a 5-mm margin lateral to the lateral ventricles as previously described [15, 16]. The hippocampus and amygdala were contoured according to previously published guidelines [17]. The hypothalamus and thalamus were contoured in accordance with previously published contouring landmarks [18, 19]. Brain structures were contoured including supraentorial and infratentorial brain areas. The brainstem comprised the midbrain, pons, and medulla oblongata. The pituitary gland,
Table 1 Patient characteristics

\begin{tabular}{ll}
\hline Cofactors & All $n=74(\%)$ \\
\hline Gender & $39(52.7)$ \\
Male & $35(47.3)$ \\
Female & $31.2(2.0-64.2)$ \\
Median age in years (range) & $43(58.1)$ \\
Surgical resection & $11(14.9)$ \\
Gross total resection & $31(41.9)$ \\
Subtotal resection & $2(2.7)$ \\
Resection status unclear & $30(40.5)$ \\
Biopsy & $185.2(11.8-709.6)$ \\
Median PTV volume in ml (range) & $54.0(50.4-60)$ \\
Median total dose in Gy (range) & $1.8(1.8-2.0)$ \\
Median single dose in Gy (range) &
\end{tabular}

$P T V$ planning target volume

cochlear IL and CL, optic nerves, and chiasm were identified and contoured following previously published recommendations [20]. Treatment planning was performed by a single experienced radiation therapist using the Oncentra MasterPlan ${ }^{\circledR}$ (Nucletron, Columbia, SC, USA) planning system, version 4.5 , with a collapsed cone algorithm for 3D photon treatment planning. In 3D-CRT, beam directions were carefully selected and consisted of four to five coplanar and non-coplanar fields in the majority of cases and, if necessary, subfields, using a field-in-field (FIF) technique. For all patients, 6-MV photons were used. Treatment planning for proton therapy was performed using the treatment planning system Syngo PT Planning (Siemens). For the plan comparison, ion beams were applied using a horizontal beam or the gantry. Two to three coplanar or non-coplanar beams were used for the particle therapy treatment. The gantry rotation was not restricted in the coplanar and noncoplanar settings. The pencil beams chosen for the PRT typically had a lateral full width at half maximum (FWHM) of $10 \mathrm{~mm}$. The treatment table position was restricted to between 10 and 170 degrees to avoid collisions of the horizontal beam nozzle with the table. To assure comparability, the same target volumes and OAR were used for particle and photon plans. Tolerance levels for the OAR were based on the work of QUANTEC [21-25]. Planning target volume (PTV) coverage of $\geq 95 \%$ of the prescribed dose was required and in all patients, at the time of treatment planning and delivery, the additional OAR were monitored but not considered an avoidance structure in either radiotherapy modality.

\section{Treatment plan evaluation}

Qualitative and quantitative dose evaluations were conducted for both radiotherapy modalities. Dose-volume histograms (DVHs) were constructed for all volumes, and 
dose parameters were extracted to check for proper target volume coverage and to assure compliance with the OAR dose constraints. PTV coverage was assessed utilizing measurement of the volume receiving $\geq 90 \%, \geq 95 \%$, and $\geq 100 \%$ of the prescribed relative doses (in \%). Confirmation of PTV dose distribution was evaluated by calculating $\mathrm{HI}$ and IC.

Homogeneity index $(H I)=\frac{\mathrm{D}_{5}-\mathrm{D}_{95}}{\mathrm{Dp}} \times 100$

Inhomogeneity coefficient $(I C)=\frac{\mathrm{D}_{\max }-\mathrm{D}_{\text {min }}}{\mathrm{D}_{\text {mean }}}$

$D_{5}$ and $D_{95}$ are the minimum doses in $5 \%$ and $95 \%$ of the PTV, respectively, and $D_{p}$ is the prescribed dose in the PTV. The ideal HI value is zero, where $\mathrm{D}_{5}$ equals $\mathrm{D}_{95}$ [26]. The IC assesses the distribution variance of the PTV dose, where higher values indicate greater variability [27]. $D_{\max }$ and $D_{\min }$ represent the maximum and minimum doses in the PTV, respectively, and $D_{\text {mean }}$ equals the average PTV dose.

$$
\text { Integraldose }(I D)=\sum_{i} \mathrm{D}_{\text {mean }} \times V_{i}
$$

The integral dose (ID) is defined as the sum of the mean dose multiplied by the volume if the voxels are assumed to be the same size and the organ is hypothesized to have a uniform density. The ID also represents the area under the DVH curve at all dose levels [28] and allows evaluation of the lower dose spread compared to conventional measurements. $D_{\text {mean }}$ equals the average dose of the target volume or OAR, and $\mathrm{V}_{\mathrm{i}}$ is defined as the structure volume in $\mathrm{ml}$. The simplified formula was used in this analysis: $D_{\text {mean }} \times$ volume.

\section{Data management and automatic dose-volume analysis}

All PRT data and additional treatment information were available in the central research database of the authors' department, which functioned as the central data source like previously described [29]. Project-specific OAR re-contouring and 3D-CRT data were additionally imported into the central research database after re-planning. Dose-volume analysis was performed automatically on a central analysis platform directly connected to the central research database like previously described [30]. A workflow was designed to analyze the radiotherapeutic imaging data (RT data) of all patients with the abovementioned recontouring. First, RT data was retrieved from the central research database and preprocessed for analysis. During analysis, dose statistics and DVHs were calculated automatically. All results were written into the central storage of the analysis platform. Finally, results for all patients were summarized in a single result file for further statistical analysis.

\section{Ethics}

The study was approved by the Ethics Committee, University of Heidelberg (no. S-056/2015).

\section{Statistical analysis}

Statistical analysis was carried out with SigmaPlot ${ }^{\mathrm{TM}}$ (Systat Software GmbH, Erkrath, Germany) software. The Wilcoxon signed-rank test was applied for analysis with corresponding two-sided $95 \%$ confidence intervals. A $p$ value $<0.05$ was considered statistically significant.

Table 2 Comparison of target volume coverage

\begin{tabular}{lll}
\hline & 3D-CRT & PRT \\
\hline $\mathrm{V}_{90 \%}($ in $\%)$ & $96.10 \pm 3.56$ & $97.54 \pm 3.26$ \\
$\mathrm{~V}_{95 \%}($ in $\%)$ & $94.62 \pm 5.95$ & $96.36 \pm 5.26$ \\
$\mathrm{~V}_{100 \%}($ in $\%)$ & $85.12 \pm 12.08$ & 0.238 \\
$\mathrm{D}_{\max }($ in $\%)$ & $105.81 \pm 2.82$ & 0.361 \\
$\mathrm{D}_{\operatorname{mean}}($ in $\%)$ & $99.66 \pm 1.89$ & $106.56 \pm 2.45$ \\
$\mathrm{D}_{\min }($ in $\%)$ & $85.23 \pm 12.08$ & $99.78 \pm 1.39$ \\
$\mathrm{HI}($ in $\%)$ & $8.85 \pm 5.62$ & $84.90 \pm 12.21$ \\
$\mathrm{IC}$ (in $\%)$ & $0.21 \pm 0.13$ & $5.84 \pm 5.42$ \\
\hline
\end{tabular}

Values are given as mean values with standard deviations

*Indicates a statistically significant $p$-value

$3 D$-CRT three-dimensional conventional radiotherapy, $P R T$ proton beam therapy, $V 90 \%$ percentage of planning target volume (PTV) that receives a minimum of $90 \%$ of the prescribed dose, $V_{95} \%$ percentage of PTV that receives a minimum of $95 \%$ of the prescribed dose, $V_{100} \%$ percentage of PTV that receives a minimum of $100 \%$ of the prescribed dose, $D_{\text {max }}$ maximum dose to the PTV, $D_{\text {mean }}$ average dose to the PTV, $D_{\text {min }}$ minimum dose to the PTV, HI homogeneity index: (D5\%-D95\%)/prescribed dose $\times 100, I C$ inhomogeneity coefficient: $\left(\mathrm{D}_{\max }-\mathrm{D}_{\min }\right) / \mathrm{D}_{\operatorname{mean}}$ 


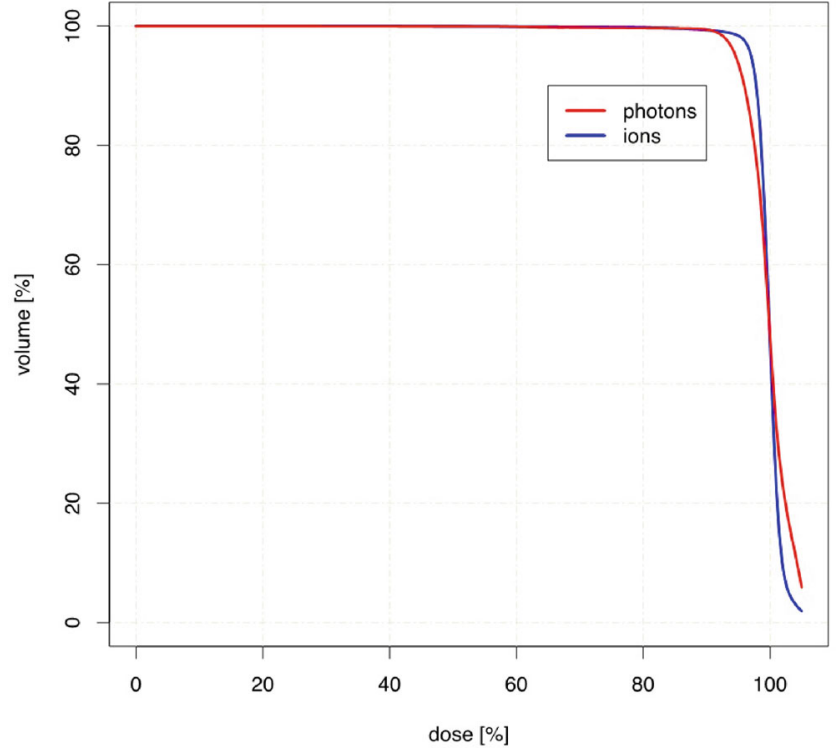

Fig. 1 Cumulative dose-volume histogram DVH $(n=74)$ comparing planning target coverage for both proton beam therapy $(P R T)$ and three-dimensional conventional radiotherapy $(3 D-C R T)$

\section{Results}

\section{PTV coverage}

Target volume coverage was comparable in both treatment modalities. No statistically significant difference could be detected regarding $\mathrm{V}_{90} \%$ and $\mathrm{V}_{95} \%$ (percentage of PTV receiving a minimum of 90 and $95 \%$ of the prescribed dose, respectively). Similar findings for values can be identified by comparing the HI and IC (Table 2). Although not significant, when comparing the cumulative DVH for PTV, slightly better target coverage as well as a lower maximum dose for protons can be observed (Fig. 1).

\section{Sparing organs at risk}

\section{Critical organs of the central nervous system}

Dose-limiting OAR with limiting tolerance doses and regions at risk of secondary malignancies were assessed to compare both treatment modalities (Table 3 and Fig. 4). PRT allowed for significant sparing of critical IL and CL auditory organs. Here, the $\mathrm{D}_{\max }$ and ID doses were decreased by 21.6 and $38.1 \%$ IL, and 63.7 and $74.1 \% \mathrm{CL}$, respectively. Similar results were seen for the optical system,

Table 3 Dose comparison of organs at risk

\begin{tabular}{|c|c|c|c|c|c|}
\hline Organ at risk & & $\begin{array}{l}\text { 3D-CRT } \\
\text { (relative dose in } \% \pm \mathrm{SD} \text { ) }\end{array}$ & $\begin{array}{l}\text { PRT } \\
\text { (relative dose in } \% \pm \mathrm{SD} \text { ) }\end{array}$ & $\begin{array}{l}\text { 3D-CRT vs. PRT } \\
\text { (difference in \%) }\end{array}$ & $p$-value \\
\hline \multirow[t]{3}{*}{ Optic nerve ipsilateral } & $D_{\max }$ & $64.4 \pm 35.5$ & $56.2 \pm 39.0$ & -12.8 & 0.165 \\
\hline & $\mathrm{D}_{\text {mean }}$ & $38.4 \pm 28.3$ & $33.0 \pm 28.5$ & -14.0 & $<0.001^{*}$ \\
\hline & Mean ID & $62.8 \pm 61.0$ & $54.7 \pm 59.5$ & -12.9 & 0.480 \\
\hline \multirow[t]{3}{*}{ Optic nerve contralateral } & $\mathrm{D}_{\max }$ & $56.5 \pm 33.9$ & $36.4 \pm 36.7$ & -35.6 & $<0.001^{*}$ \\
\hline & $\mathrm{D}_{\text {mean }}$ & $26.4 \pm 22.0$ & $14.8 \pm 20.1$ & -44.0 & $<0.001^{*}$ \\
\hline & Mean ID & $43.2 \pm 43.7$ & $25.6 \pm 44.7$ & -40.7 & $0.008^{*}$ \\
\hline \multirow[t]{3}{*}{ Inner ear ipsilateral } & $\mathrm{D}_{\max }$ & $56.8 \pm 33.4$ & $44.5 \pm 37.6$ & -21.6 & $0.015^{*}$ \\
\hline & $D_{\text {mean }}$ & $43.4 \pm 29.5$ & $26.3 \pm 26.9$ & -39.3 & $<0.001^{*}$ \\
\hline & Mean ID & $61.6 \pm 43.1$ & $38.1 \pm 41.4$ & -38.1 & $<0.001^{*}$ \\
\hline \multirow[t]{3}{*}{ Inner ear contralateral } & $D_{\max }$ & $34.6 \pm 23.1$ & $12.5 \pm 22.8$ & -63.7 & $<0.001^{*}$ \\
\hline & $\mathrm{D}_{\text {mean }}$ & $24.9 \pm 18.8$ & $7.2 \pm 15.3$ & -71.0 & $<0.001^{*}$ \\
\hline & Mean ID & $35.7 \pm 31.1$ & $9.2 \pm 19.7$ & -74.1 & $<0.001^{*}$ \\
\hline \multirow[t]{3}{*}{ Optic chiasm } & $\mathrm{D}_{\max }$ & $76.6 \pm 28.8$ & $66.8 \pm 35.7$ & -12.7 & $0.033 *$ \\
\hline & $\mathrm{D}_{\text {mean }}$ & $63.5 \pm 29.8$ & $44.5 \pm 33.8$ & -30.0 & $<0.001^{*}$ \\
\hline & Mean ID & $146.1 \pm 96.4$ & $109.2 \pm 103.2$ & -25.2 & $0.017 *$ \\
\hline \multirow[t]{3}{*}{ Thalamus ipsilateral } & $\mathrm{D}_{\max }$ & $82.4 \pm 27.0$ & $83.5 \pm 26.6$ & 1.3 & 0.059 \\
\hline & $\mathrm{D}_{\text {mean }}$ & $66.7 \pm 31.3$ & $58.8 \pm 32.8$ & -11.9 & $<0.001 *$ \\
\hline & Mean ID & $498.0 \pm 266.1$ & $433.1 \pm 270.5$ & -13.0 & $0.025^{*}$ \\
\hline \multirow[t]{3}{*}{ Thalamus contralateral } & $D_{\max }$ & $76.2 \pm 27.9$ & $69.3 \pm 35.2$ & -9.0 & 0.598 \\
\hline & $\mathrm{D}_{\text {mean }}$ & $54.5 \pm 27.7$ & $32.9 \pm 29.1$ & -39.7 & $<0.001 *$ \\
\hline & Mean ID & $419.4 \pm 241.6$ & $260.5 \pm 243.9$ & -37.9 & $<0.001^{*}$ \\
\hline \multirow[t]{3}{*}{ SVZ ipsilateral } & $D_{\max }$ & $88.9 \pm 19.0$ & $86.3 \pm 22.1$ & -3.0 & 0.301 \\
\hline & $\mathrm{D}_{\text {mean }}$ & $57.9 \pm 30.8$ & $50.5 \pm 31.2$ & -12.9 & $<0.001^{*}$ \\
\hline & Mean ID & $765.5 \pm 552.4$ & $731.9 \pm 639.9$ & -4.4 & 0.069 \\
\hline
\end{tabular}


Table 3 Dose comparison of organs at risk (Continued)

\begin{tabular}{|c|c|c|c|c|c|}
\hline Organ at risk & & $\begin{array}{l}\text { 3D-CRT } \\
\text { (relative dose in } \% \pm \mathrm{SD} \text { ) }\end{array}$ & $\begin{array}{l}\text { PRT } \\
\text { (relative dose in } \% \pm \mathrm{SD} \text { ) }\end{array}$ & $\begin{array}{l}\text { 3D-CRT vs. PRT } \\
\text { (difference in \%) }\end{array}$ & $p$-value \\
\hline \multirow[t]{3}{*}{$\overline{\text { SVZ contralateral }}$} & $\mathrm{D}_{\max }$ & $75.5 \pm 23.7$ & $61.4 \pm 36.0$ & -18.7 & $0.006^{*}$ \\
\hline & $\mathrm{D}_{\text {mean }}$ & $38.2 \pm 21.9$ & $16.8 \pm 18.7$ & -56.1 & $<0.001^{*}$ \\
\hline & Mean ID & $531.7 \pm 342.4$ & $246.9 \pm 350.6$ & -53.6 & $<0.001^{*}$ \\
\hline \multirow[t]{3}{*}{ Hypothalamus } & $D_{\max }$ & $78.9 \pm 27.1$ & $72.5 \pm 35.4$ & -8.2 & 0.494 \\
\hline & $\mathrm{D}_{\text {mean }}$ & $67.6 \pm 29.6$ & $50.4 \pm 35.2$ & -25.5 & $<0.001 *$ \\
\hline & Mean ID & $192.9 \pm 107.2$ & $144.2 \pm 117.2$ & -25.2 & $<0.001^{*}$ \\
\hline \multirow[t]{3}{*}{ Hippocampus ipsilateral } & $\mathrm{D}_{\max }$ & $84.6 \pm 22.0$ & $80.0 \pm 29.5$ & -5.5 & 0.610 \\
\hline & $\mathrm{D}_{\text {mean }}$ & $64.0 \pm 30.5$ & $54.2 \pm 35.9$ & -15.3 & $<0.001^{*}$ \\
\hline & Mean ID & $391.7 \pm 207.8$ & $327.2 \pm 229.8$ & -16.5 & 0.060 \\
\hline \multirow[t]{3}{*}{ Hippocampus contralateral } & $D_{\max }$ & $64.7 \pm 24.7$ & $40.6 \pm 39.2$ & -37.2 & $<0.001^{*}$ \\
\hline & $\mathrm{D}_{\text {mean }}$ & $39.1 \pm 21.6$ & $13.9 \pm 21.6$ & -64.5 & $<0.001 *$ \\
\hline & Mean ID & $248.6 \pm 149.8$ & $92.8 \pm 156.7$ & -62.7 & $<0.001^{*}$ \\
\hline \multirow[t]{3}{*}{ Amygdala ipsilateral } & $D_{\max }$ & $77.0 \pm 29.3$ & $70.0 \pm 36.5$ & -9.2 & 0.128 \\
\hline & $\mathrm{D}_{\text {mean }}$ & $69.1 \pm 32.3$ & $59.9 \pm 38.1$ & -13.3 & $<0.001^{*}$ \\
\hline & Mean ID & $52.0 \pm 39.5$ & $48.0 \pm 47.8$ & -7.7 & 0.075 \\
\hline \multirow[t]{3}{*}{ Amygdala contralateral } & $\mathrm{D}_{\max }$ & $60.4 \pm 30.0$ & $39.2 \pm 41.0$ & -35.0 & $<0.001^{*}$ \\
\hline & $\mathrm{D}_{\text {mean }}$ & $49.5 \pm 28.5$ & $26.6 \pm 34.0$ & -46.3 & $<0.001^{*}$ \\
\hline & Mean ID & $41.0 \pm 35.5$ & $25.4 \pm 41.9$ & -37.9 & $<0.001^{*}$ \\
\hline \multirow[t]{3}{*}{ Lateral ventricle ipsilateral } & $D_{\max }$ & $89.1 \pm 18.6$ & $88.0 \pm 20.8$ & -1.3 & 0.841 \\
\hline & $\mathrm{D}_{\text {mean }}$ & $59.0 \pm 30.2$ & $50.0 \pm 29.5$ & -15.2 & $<0.001 *$ \\
\hline & Mean ID & $1085.9 \pm 1306.3$ & $976.6 \pm 1009.1$ & -10.1 & $0.035^{*}$ \\
\hline \multirow[t]{3}{*}{ Lateral ventricle contralateral } & $\mathrm{D}_{\max }$ & $81.3 \pm 22.4$ & $75.9 \pm 30.0$ & -6.7 & 0.315 \\
\hline & $\mathrm{D}_{\text {mean }}$ & $45.6 \pm 24.9$ & $25.0 \pm 22.9$ & -45.3 & $<0.001 *$ \\
\hline & Mean ID & $896.3 \pm 833.3$ & $511.3 \pm 687.4$ & -42.9 & $<0.001^{*}$ \\
\hline \multirow[t]{3}{*}{ Supratentorial } & $\mathrm{D}_{\max }$ & $103.4 \pm 10.4$ & $103.7 \pm 12.8$ & +0.3 & 0.386 \\
\hline & $D_{\text {mean }}$ & $37.8 \pm 19.6$ & $24.5 \pm 14.8$ & -35.2 & $<0.001 *$ \\
\hline & Mean ID & $45154.0 \pm 24207.3$ & $29958.7 \pm 19079.9$ & -33.7 & $<0.001 *$ \\
\hline \multirow[t]{3}{*}{ Infratentrorial } & $D_{\max }$ & $90.5 \pm 25.7$ & $88.1 \pm 32.8$ & -2.7 & 0.447 \\
\hline & $\mathrm{D}_{\text {mean }}$ & $33.5 \pm 18.7$ & $14.3 \pm 19.0$ & -57.5 & $<0.001 *$ \\
\hline & Mean ID & $7388.1 \pm 6400.3$ & $3818.6 \pm 10575.3$ & -48.3 & $<0.001 *$ \\
\hline \multirow[t]{3}{*}{ Pituitary gland } & $\mathrm{D}_{\max }$ & $65.3 \pm 33.8$ & $49.2 \pm 38.2$ & -24.6 & $0.003^{*}$ \\
\hline & $\mathrm{D}_{\text {mean }}$ & $57.8 \pm 33.4$ & $34.1 \pm 35.1$ & -40.9 & $<0.001 *$ \\
\hline & Mean ID & $34.7 \pm 27.4$ & $21.6 \pm 25.8$ & -37.8 & $<0.001 *$ \\
\hline \multirow[t]{3}{*}{ Brain stem } & $\mathrm{D}_{\max }$ & $86.4 \pm 16.7$ & $79.4 \pm 27.5$ & -8.2 & 0.153 \\
\hline & $\mathrm{D}_{\text {mean }}$ & $51.7 \pm 23.1$ & $28.1 \pm 26.3$ & -45.6 & $<0.001 *$ \\
\hline & Mean ID & $1467.4 \pm 947.2$ & $775.9 \pm 761.2$ & -47.1 & $<0.001^{*}$ \\
\hline \multirow[t]{3}{*}{ Brain } & $\mathrm{D}_{\max }$ & $105.8 \pm 2.9$ & $106.4 \pm 3.1$ & +0.6 & 0.447 \\
\hline & $\mathrm{D}_{\text {mean }}$ & $37.2 \pm 17.2$ & $23.1 \pm 12.3$ & -38.0 & $<0.001 *$ \\
\hline & Mean ID & $52898.6 \pm 24823.9$ & $33100.1 \pm 18828.2$ & -37.4 & $<0.001 *$ \\
\hline
\end{tabular}

*Indicates a statistically significant $p$-value.

$3 D$-CRT three-dimensional conventional radiotherapy, $P R T$ proton beam therapy, $D_{\max }$ maximum dose to the planning target volume (PTV), $D_{\text {mean }}$ average dose to the PTV, $D_{\text {min }}$ minimum dose to the PTV, $I D$ integral dose, $S V Z$ subventricular zone, $S D$ standard deviation

where the dose to the optic nerve (ON) CL and optic chiasm were decreased by $35.6 \%\left(\mathrm{D}_{\max }\right), 44.0 \%\left(\mathrm{D}_{\text {mean }}\right)$, and $40.7 \%$ (ID); and $12.7 \%$ ( $\mathrm{D}_{\max }$ ), $30.0 \%$ ( $\mathrm{D}_{\text {mean }}$ ), and $25.2 \%$ (ID), respectively. Findings for the IL ON did not reach statistical significance. PRT reduced the $\mathrm{D}_{\max }$ and ID to the centrally located pituitary gland by 24.6 and $37.8 \%$, respectively. Normal brain tissue, as a potential risk area for secondary malignancies, could be spared significantly. Here, the ID to supratentorial and infratentorial brain areas could be reduced by 33.7 and $48.3 \%$, respectively (each $<0.001)$. Similar decreases in $\mathrm{D}_{\text {mean }}(45.6$ and $38.0 \%)$ and ID (47.1 and $37.4 \%$ ) followed for the brainstem and whole brain, respectively (each $<0.001$ ). Cumulative DVHs are shown in Figs. 2 and 3. 

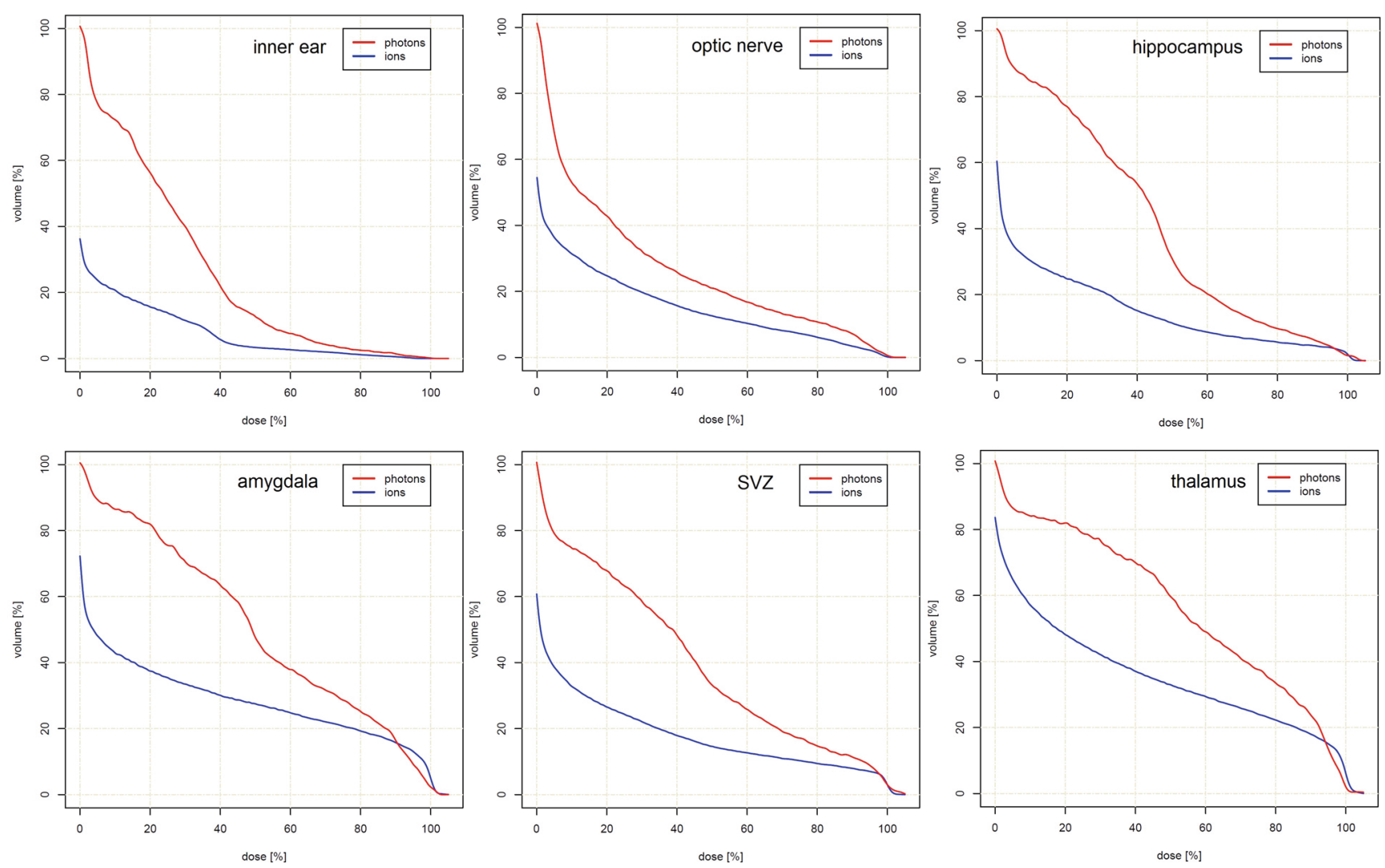

Fig. 2 Cumulative dose-volume histograms for contralateral organs at risk showing a significant dose reduction for proton beam therapy compared to three-dimensional conventional radiotherapy. SVZ subventricular zone

\section{Critical organs of neurogenesis}

It has been shown that neuronal stem cells-initiating cells for neurogenesis even in adult individuals-are extremely sensitive [31] and show diverse recovery behaviors after exposure to ionizing radiation [32]. Sparing of the IL SVZ was only significant for $\mathrm{D}_{\text {mean }}(-12.9 \%)$. However, $\mathrm{D}_{\max }$ and ID of the CL SVZ could be reduced by $18.7 \%(<0.001)$ and $53.6 \%(<0.001)$, respectively, using PRT. The second anatomic region that has been shown to harbor neuronal stem cells is the dentate gyrus in the hippocampal formation. For the CL hippocampus, doses could be reduced by $D_{\max }: 37.2 \%$, $D_{\text {mean }}: 64.5 \%$, and ID: $62.7 \%$ (each $<0.001$ ). For the IL hippocampus, only the $\mathrm{D}_{\text {mean }}$ to the hippocampus could be decreased significantly at $15.3 \%$ by applying a PRT plan $(<0.001)$.

\section{Critical structures of neurocognitive functions}

$\mathrm{D}_{\max }(35.0 \%), \mathrm{D}_{\text {mean }}(46.3 \%)$, and ID (37.9\%) to the CL amygdala could be spared using proton plans. Analogous to other IL structures, the IL amygdala had reductions of $\mathrm{D}_{\text {mean }}$ by only $13.3 \%(<0.001)$. Again, sparing of the CL thalamus was superior to sparing of the IL thalamus when using PRT plans. Relative decreases of $\mathrm{D}_{\text {mean }}: 39.7 \%$ and ID: $37.9 \%$ (each $<0.001$ ) in the CL thalamus and $\mathrm{D}_{\text {mean }}$ : $13.0 \%$ and ID: $11.9 \%$ ( $p=0.025$ and $p<0.001$, respectively) in the IL thalamus could be achieved.

\section{Pilocytic astrocytoma versus other LGG}

When assigning the patient collective further into pilocytic astrocytoma $(n=28)$ and other LGG $(n=46)$, the latter could be spared more effectively with PRT than the former. In detail, in the CL hippocampus ( $D_{\max }:-97.6 \%$ vs. $-60.5 \%, \mathrm{D}_{\text {mean }}:-79.2 \%$ vs. $-3.0 \%$, ID: $-97.8 \%$ vs. $-61.1 \%)$, CL amygdala ( $\mathrm{D}_{\max }:-96.2 \%$ vs. $-33.3 \%$, ID: $-95.6 \%$ vs. $-36.7 \%$ ), brainstem ( $\mathrm{D}_{\max }:-77.2 \%$ vs. $-23.9 \%$, ID: $-76.7 \%$ vs. $-23.3 \%$ ), pituitary gland ( $\mathrm{D}_{\text {mean }}$ : $-45.5 \%$ vs. $-3.6 \%$, ID: $-70.5 \%$ vs. $-12.6 \%$ ) and optic chiasm ( $\mathrm{D}_{\max }:-37.5 \%$ vs. $\left.-16.6 \%\right)$, the dose reduction with PRT was more pronounced for non-pilocytic astrocytoma. Only in the IL hippocampus ( $\mathrm{D}_{\max }:+4.5 \%$ vs. $-20.8 \%)$ and IL inner ear ( $D_{\text {mean }}:-6.6 \%$ vs. $\left.-27.3 \%\right)$ did PRT decrease the dose in a more pronounced manner in pilocytic astrocytoma. 

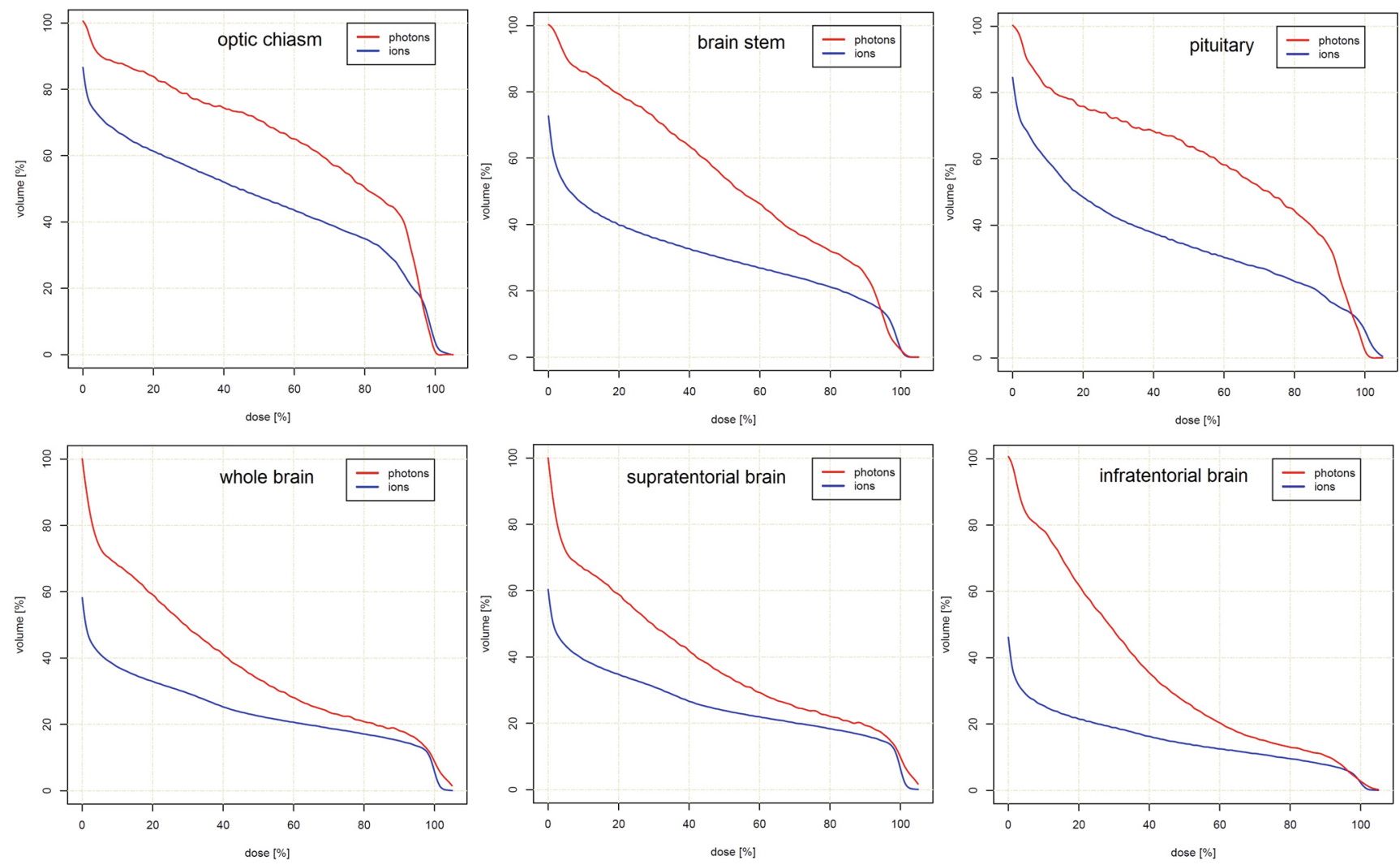

Fig. 3 Cumulative dose-volume histograms for unifocal organs at risk showing a significant dose reduction for proton beam therapy compared to three-dimensional conventional radiotherapy

\section{Discussion}

These data present an overwhelming dosimetric advantage of PRT over 3D-CRT in terms of sparing not only stem cell niches, but also nearly any other OAR. In addition to the significant reduction of mean dose and the ID bilaterally, particularly on the CL side, the maximum dose could be lowered. PRT offers distinct biophysical advantages over conventional 3D-CRT. However, to what extent this will have a clinical impact remains to be proven by long-term observations. Particular attention must be paid to structures that are considered essential for neurocognitive functions, such as the hippocampus or the SVZ.

There are several reports of treatment planning comparisons for various entities. Boehling et al., for example, investigated the dose distribution in 10 representative cases of pediatric craniopharyngioma for nearby critical structures when using PRT instead of intensity modulated radiotherapy with photons. Their study showed a reduction of the ID received by the hippocampus of up to $51 \%$ and up to $57 \%$ for the SVZ [33], whereby intensity modulated PRT had the largest potential for relative dose reduction. Another study published by Fuss et al. performed a dosimetric comparison for optic pathway glioma focusing on the saving potential for the CL ON, showing that PRT has the potential to nearly halve the dose received $(-47 \%)$ [34]. A decrease in ID was also noted for the chiasm $(-11 \%)$ and the pituitary $(-13 \%)$. Likewise, dosimetric superiority for the whole brain, temporal lobes, chiasm, and cochlea could be demonstrated in both supratentorial and infratentorial locations [10, 35, 36]. The ID represents a valuable option for considering OAR volumes in the dosimetric assessment. Here the ID should offer objective values, which allow for improved evaluation of lower dose spreads compared to $\mathrm{D}_{\text {mean }}$ or median dose. However, even the ID is not able to predict normal toxicity complication probability (NTCP) without correlation of clinical long-term toxicity data. All of these reports are in accordance with the presented findings that there is no difference between photon and proton plans with regard to target coverage, all the more, however, for the CL OAR, particularly when using intensity modulated PRT instead of 3D-PRT.

It is well known that the risk of occurrence and the severity of radiation-related impairment of neurocognitive function are correlated with both the dose and the irradiated volume of critical structures, such as the supratentorial brain in general, or the hippocampus in particular. Especially in children, a decrease in intelligence quotient (IQ), processing speed, and fine motor skills has been reported [37-39]. Our particular focus was on the exposure of structures con- 

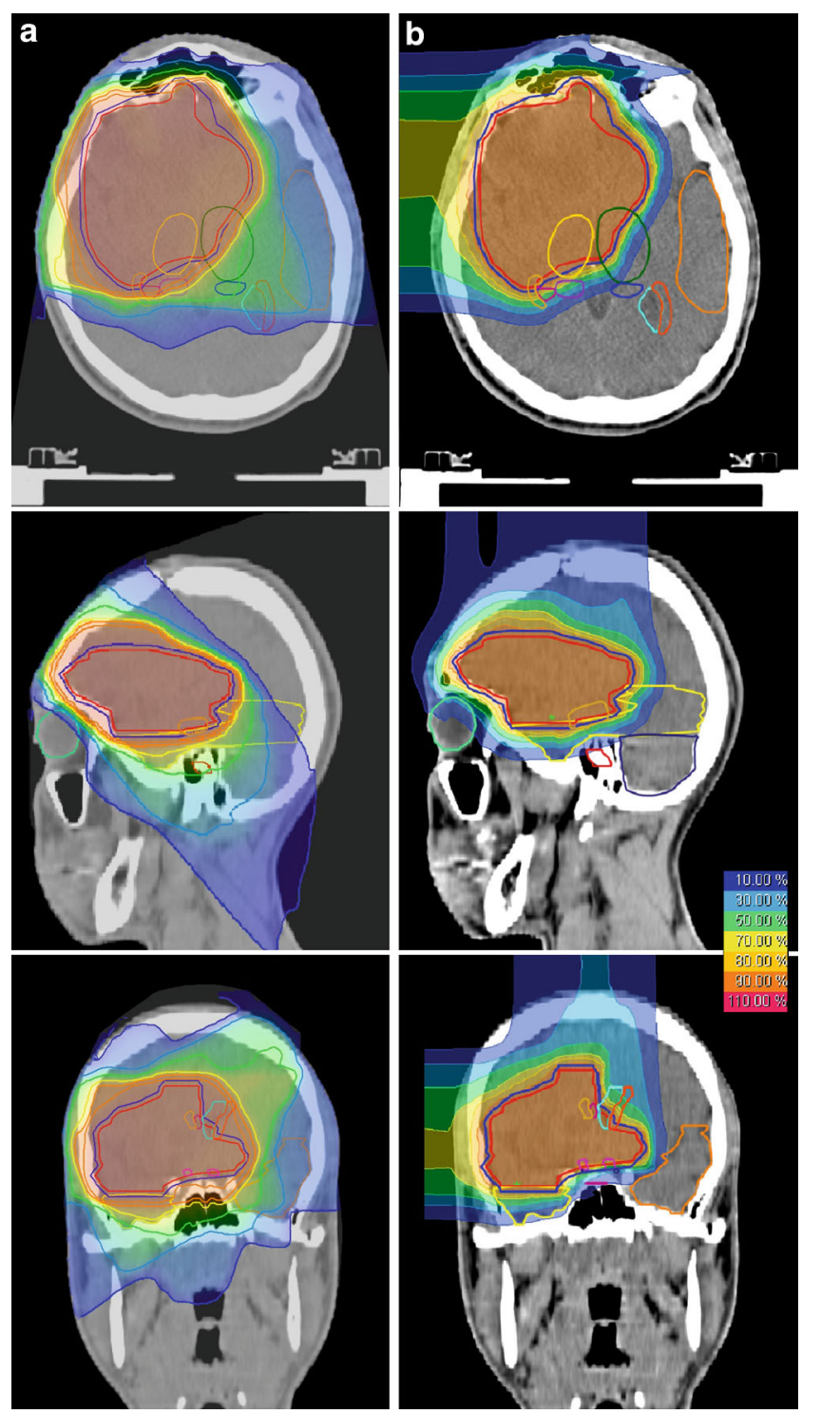

Fig. 4 Comparison of dose distribution for a patient with low grade glioma. a Three-dimensional conventional radiotherapy plan, b proton beam therapy plan. CTV is delineated in red, the corresponding planning target volume in blue. The potential for dose reduction is especially eminent at the contralateral site

sidered crucial for neurocognitive performance, such as the hippocampus, SVZ, amygdala, and thalamus. In contrast to a general assessment of dose distribution (whole brain, supratentorial, infratentorial, temporal lobe), a more detailed analysis substantiated by clinical parameters could lead to a better understanding and risk assessment for the occurrence of neurocognitive impairment. Merchant et al. showed that the dose reduction achieved by PRT has the potential to mitigate neurocognitive impairment. The authors collected dosimetric information for 40 patients with different types of childhood brain tumors and calculated the estimated decline in their full scale IQs using dosedependent cognitive effect models [40]. The reason for ra- diation-induced neurocognitive impairment is most likely multifactorial [13, 39]; however, there is growing evidence that supports the idea that neural progenitor cells (NPCs) in stem cell niches play an important role. The hippocampus and the SVZ are known areas of origin for NPCs [11, 12]. Although their role has not yet been fully elucidated, it is hypothesized that their capability for self-renewal and injury repair is of central importance to the genesis of longterm neurocognitive effects $[41,42]$. To counteract a radiogenic impairment of their recovery potential, every effort should be made to decrease the dose received by the NPCs. While there is substantiated data for the correlation between dose and hippocampus, the role of the SVZ is disputed more vigorously [43]. One of the reasons is attributed to its potential to contribute to tumor propagation [44].

As the current findings show, inter alia, PRT is an excellent treatment option that does not compromise target coverage. Furthermore, these data underline that sparing of cerebral OAR is more pronounced in the group of LGG compared to pilocytic astrocytoma, which arise mainly from midline structures. Here, PRT allows for improved sparing of centrally localized neuronal structures like the hippocampus, optic chiasm, brainstem, and pituitary gland. Preliminary results from the prospective Radiation Therapy Oncology Group (RTOG 0933) described the effect of hippocampal sparing during whole brain irradiation and concluded that decreased short-term memory impairment compared to historical controls is attributed to sparing of stem cell niches [45]. Whether, and how, these preliminary results will be reflected in a clinically relevant decrease of treatment-related long-term toxicity remains to be seen and, of course, substantiated by long-term results.

Although the present findings provide strong evidence in favor of PRT, their limitations should be considered. First, following the recommendation of the German Society of Radiation Oncology (DEGRO), PRT should be used subject to disease, localization and availability of patients with LGG, as they are particularly appropriate candidates. LGG is the most common diagnosis of central nervous system malignancy in pediatric patients and the use of radiotherapy must inevitably be considered, especially in patients presenting with an unfavorable or irresectable tumor location. In keeping with that recommendation, this study was performed retrospectively. Second, the analysis compared photons to protons in general, and this does not demonstrate the full potential of each technique. A more detailed evaluation of the role of intensity modulation for both photons and protons is planned as the next step. Equally interesting would be the possibility of taking the sensitive OAR into consideration for treatment planning initially and also consideration of whether there is an additional potential for sparing OAR with protons, as is well-known from earlier 
planning studies with photons based on the motto that "seeing is saving."

The strength of this study is its large number of patients with proven LGG. To our knowledge, this is the largest case series of LGG patients, providing valuable dosimetric information because of its homogenous distribution to all lobes of the brain. To minimize interobserver variability, all OAR and all treatment plans were contoured/performed by the same experienced radiation oncologist. In addition, automated analysis of treatment-related data using a central research database and the task-customized workflow minimized potential transmission or inadvertent errors. The information obtained by the presented analysis is not only helpful for identifying patients who would potentially benefit from PRT, but also provides important arguments in interdisciplinary discussions about why the effort should be made to expand access to PRT.

However, as previously stated, the availability of proton centers remains limited. This is why the authors' goal is to acquire new data and correlate dosimetric information with functional outcomes, potentially providing further selection criteria for patients who would benefit significantly from PRT.

\section{Conclusion}

The dose distribution of PRT is significantly superior when compared to conventional radiotherapy, particularly with regard to OAR that are considered essential for neurologic function and neurocognition, or which play an important role in terms of quality of life. PRT might hereby lead to reduced treatment-related side effects.

Acknowledgements We thank Eric Tonndorf-Martini and Thomas Mielke for excellent technical assistance. We acknowledge financial support of the Dietmar-Hopp-Stiftung.

\section{Compliance with ethical guidelines}

Conflict of interest S.B. Harrabi, N. Bougatf, A. Mohr, T. Haberer, K. Herfarth, S.E. Combs, J. Debus, and S. Adeberg state that there are no conflicts of interest.

Ethical standards All studies on humans described in the present manuscript were carried out with the approval of the responsible ethics committee and in accordance with national law and the Helsinki Declaration of 1975 (in its current, revised form).

Open Access This article is distributed under the terms of the Creative Commons Attribution 4.0 International License (http:// creativecommons.org/licenses/by/4.0/), which permits unrestricted use, distribution, and reproduction in any medium, provided you give appropriate credit to the original author(s) and the source, provide a link to the Creative Commons license, and indicate if changes were made.

\section{References}

1. Fisher PG, Tihan T, Goldthwaite PT, Wharam MD, Carson BS, Weingart JD, Repka MX, Cohen KJ, Burger PC (2008) Outcome analysis of childhood low-grade astrocytomas. Pediatr Blood Cancer 51(2):245-250

2. Merchant TE, Kun LE, Wu S, Xiong X, Sanford RA, Boop FA (2009) Phase II trial of conformal radiation therapy for pediatric low-grade glioma. J Clin Oncol 27(22):3598-3604

3. Gnekow AK, Falkenstein F, Hornstein S von, Zwiener I, Berkefeld S, Bison B, Warmuth-Metz M, Driever PH, Soerensen N, Kortmann R-D et al (2012) Long-term follow-up of the multicenter, multidisciplinary treatment study HIT-LGG-1996 for low-grade glioma in children and adolescents of the German Speaking Society of Pediatric Oncology and Hematology. Neuro-Oncology 14(10):1265-1284

4. Gnekow AK (2003) Therapie von Gliomen niedriger Malignität im Kindes- und Jugendalter. WIR Informationsschrift Aktion für Krebskranke Kinder eV (Bonn) 2:8

5. National Cancer Institute NIoH: Phase II Study of ReducedField Conformal Radiotherapy in Young Patients With Low-Grade Gliomas.

6. Laack NN, Brown PD, Ivnik RJ, Furth AF, Ballman KV, Hammack JE, Arusell RM, Shaw EG, Buckner JC (2005) Cognitive function after radiotherapy for supratentorial low-grade glioma: A North Central Cancer Treatment Group prospective study. Int J Radiat Oncol Biol Phys 63(4):1175-1183

7. Kortmann R-DMD, Timmermann B, Taylor R, Scarzello G, Plasswilm L, Paulsen F, Jeremic B, Gnekow A, Dieckmann K, Kay S et al (2003) Current and future strategies in radiotherapy of childhood low-grade glioma of the brain. Strahlenther Onkol 179(8):509-520

8. Krasin MJ, Davidoff AM, Xiong X, Wu S, Hua C-H, Navid F, Rodriguez-Galindo C, Rao BN, Hoth KA, Neel MD et al (2010) Preliminary results from a prospective study using limited margin radiotherapy in pediatric and young adult high grade non-rhabdomyosarcoma soft tissue sarcoma. Int J Radiat Oncol Biol Phys $76(3): 874-878$

9. Chan MD (2015) Recent technical advances and indications for radiation therapy in low-grade glioma. Semin Radiat Oncol 25(3):189-196

10. Eaton BR, Yock T (2014) The use of proton therapy in the treatment of benign or low-grade pediatric brain tumors. Cancer J 20(6):5

11. Kazda T, Jancalek R, Pospisil P, Sevela O, Prochazka T, Vrzal M, Burkon P, Slavik M, Hynkova L, Slampa P et al (2014) Why and how to spare the hippocampus during brain radiotherapy: the developing role of hippocampal avoidance in cranial radiotherapy. Radiat Oncol 9:139-139

12. Kut C, Janson Redmond K (2014) New considerations in radiation treatment planning for brain tumors: neural progenitor cell - containing niches. Semin Radiat Oncol 24(4):265-272

13. Ullrich NJ, Embry L (2012) Neurocognitive dysfunction in survivors of childhood brain tumors. Semin Pediatr Neurol 19(1):35-42

14. Haberer TBW, Schardt D (1993) Magnetic scanning system for heavy ion therapy. Nucl Instrum Methods Phys Res A 330(1-2):296-305

15. Barani IJ, Cuttino LW, Benedict SH, Todor D, Bump EA, Wu Y, Chung TD, Broaddus WC, Lin PS (2007) Neural stem cell-preserving external-beam radiotherapy of central nervous system malignancies. Int J Radiat Oncol Biol Phys 68(4):978-985

16. Evers P, Lee PP, DeMarco J, Agazaryan N, Sayre JW, Selch M, Pajonk F (2010) Irradiation of the potential cancer stem cell niches in the adult brain improves progression-free survival of patients with malignant glioma. BMC Cancer 10:384 
17. Chera BS, Amdur RJ, Patel P, Mendenhall WM (2009) A radiation oncologist's guide to contouring the hippocampus. Am J Clin Oncol 32(1):20-22

18. Merchant TE, Goloubeva O, Pritchard DL, Gaber MW, Xiong X, Danish RK, Lustig RH (2002) Radiation dose-volume effects on growth hormone secretion. Int J Radiat Oncol Biol Phys 52(5):1264-1270

19. Lemaire JJ, Sakka L, Ouchchane L, Caire F, Gabrillargues J, Bonny JM (2010) Anatomy of the human thalamus based on spontaneous contrast and microscopic voxels in high-field magnetic resonance imaging. Neurosurgery 66(3 Suppl Operative):161-172

20. Scoccianti S, Detti B, Gadda D, Greto D, Furfaro I, Meacci F, Simontacchi G, Di Brina L, Bonomo P, Giacomelli I et al (2015) Organs at risk in the brain and their dose-constraints in adults and in children: a radiation oncologist's guide for delineation in everyday practice. Radiother Oncol 114(2):230-238

21. Bhandare N, Jackson A, Eisbruch A, Pan CC, Flickinger JC, Antonelli P, Mendenhall WM (2010) Radiation therapy and hearing loss. Int J Radiat Oncol Biol Phys 76(3):S50-S57

22. Kirkpatrick JP, Kogel AJ van der, Schultheiss TE (2010) Radiation dose - volume effects in the spinal cord. Int J Radiat Oncol Biol Phys 76(3):S42-S49

23. Lawrence YR, Li XA, Naqa I el, Hahn CA, Marks LB, Merchant TE, Dicker AP (2010) Radiation dose - volume effects in the brain. Int J Radiat Oncol Biol Phys 76(3):S20-S27

24. Mayo C, Martel MK, Marks LB, Flickinger J, Nam J, Kirkpatrick J (2010) Radiation dose - volume effects of optic nerves and chiasm. Int J Radiat Oncol Biol Phys 76(3):S28-S35

25. Mayo C, Yorke E, Merchant TE (2010) Radiation associated brainstem injury. Int J Radiat Oncol Biol Phys 76(3):S36-S41

26. Kataria T, Sharma K, Subramani V, Karrthick KP, Bisht SS (2012) Homogeneity Index: An objective tool for assessment of conformal radiation treatments. J Med Phys 37(4):207-213

27. Claus F, Mijnheer B, Rasch C, Bortfeld T, Fraass B, De Gersem W, Wirtz H, Hoinkis C, Cho BC, Kwong LW et al (2002) Report of a study on IMRT planning strategies for ethmoid sinus cancer. Strahlenther Onkol 178(10):572-576

28. D'Souza WD, Rosen II (2003) Nontumor integral dose variation in conventional radiotherapy treatment planning. Med Phys 30(8):2065-2071

29. Kessel KA, Bohn C, Engelmann U, Oetzel D, Bougatf N, Bendl R, Debus J, Combs SE (2014) Five-year experience with setup and implementation of an integrated database system for clinical documentation and research. Computer methods and programs in biomedicine 114(2):206-217

30. Bougatf N, Bendl R, Debus J (2015) Towards secondary use of heterogeneous radio-oncological data for retrospective clinical trials: service-oriented connection of a central research database with image analysis tools. Proc SPIE 9418, Medical Imaging 2015. PACS and Imaging Informatics: Next Generation and Innovations 941807 (March 17, 2015). doi:10.1117/12.2084365

31. Mizumatsu S, Monje ML, Morhardt DR, Rola R, Palmer TD, Fike JR (2003) Extreme sensitivity of adult neurogenesis to low doses of X-irradiation. Cancer Res 63(14):4021-4027

32. Hellstrom NA, Bjork-Eriksson T, Blomgren K, Kuhn HG (2009) Differential recovery of neural stem cells in the subventricular zone and dentate gyrus after ionizing radiation. Stem Cells 27(3):634-641
33. Boehling NS, Grosshans DR, Bluett JB, Palmer MT, Song X, Amos RA, Sahoo N, Meyer JJ, Mahajan A, Woo SY (2012) Dosimetric comparison of three-dimensional conformal proton radiotherapy, intensity-modulated proton therapy, and intensity-modulated radiotherapy for treatment of pediatric craniopharyngiomas. Int J Radiat Oncol Biol Phys 82(2):643-652

34. Fuss M, Hug EB, Schaefer RA, Nevinny-Stickel M, Miller DW, Slater JM, Slater JD (1999) Proton radiation therapy (prt) for pediatric optic pathway gliomas: comparison with $3 \mathrm{~d}$ planned conventional photons and a standard photon technique. Int J Radiat Oncol Biol Phys 45(5):1117-1126

35. MacDonald SM, Safai S, Trofimov A, Wolfgang J, Fullerton B, Yeap BY, Bortfeld T, Tarbell NJ, Yock T (2008) Proton Radiotherapy for Childhood Ependymoma: Initial Clinical Outcomes and Dose Comparisons. Int J Radiat Oncol Biol Phys 71(4):979-986

36. Brower JV, Indelicato DJ, Aldana PR, Sandler E, Rotondo R, Mendenhall NP, Marcus RB, Su Z (2013) A treatment planning comparison of highly conformal radiation therapy for pediatric low-grade brainstem gliomas. Acta Oncol (Madr) 52(3):594-599

37. Merchant TE, Conklin HM, Wu S, Lustig RH, Xiong X (2009) Late effects of conformal radiation therapy for pediatric patients with low-grade glioma: prospective evaluation of cognitive, endocrine, and hearing deficits. J Clin Oncol 27(22):3691-3697

38. Armstrong GT (2010) Long-term survivors of childhood central nervous system malignancies: The experience of the Childhood Cancer Survivor Study. Eur J Paediatr Neurol 14(4):298-303

39. Jalali R, Mallick I, Dutta D, Goswami S, Gupta T, Munshi A, Deshpande D, Sarin R (2010) Factors influencing neurocognitive outcomes in young patients with benign and low-grade brain tumors treated with stereotactic conformal radiotherapy. Int J Radiat Oncol Biol Phys 77(4):974-979

40. Merchant TE, Hua C-h, Shukla H, Ying X, Nill S, Oelfke U (2008) Proton versus photon radiotherapy for common pediatric brain tumors: Comparison of models of dose characteristics and their relationship to cognitive function. Pediatr Blood Cancer 51(1):110-117

41. Goings GE, Sahni V, Szele FG (2004) Migration patterns of subventricular zone cells in adult mice change after cerebral cortex injury. Brain Res 996(2):213-226

42. Arvidsson A, Collin T, Kirik D, Kokaia Z, Lindvall O (2002) Neuronal replacement from endogenous precursors in the adult brain after stroke. Nat Med 8(9):963-970

43. Redmond KJ, Mahone EM, Terezakis S, Ishaq O, Ford E, McNutt T, Kleinberg L, Cohen KJ, Wharam M, Horska A (2013) Association between radiation dose to neuronal progenitor cell niches and temporal lobes and performance on neuropsychological testing in children: a prospective study. Neuro-Oncology 15(3):360-369

44. Chen L, Guerrero-Cazares H, Ye X, Ford E, McNutt T, Kleinberg L, Lim M, Chaichana K, Quinones-Hinojosa A, Redmond K (2013) Increased subventricular zone radiation dose correlates with survival in glioblastoma patients after gross total resection. Int J Radiat Oncol Biol Phys 86(4):616-622

45. Gondi V, Pugh SL, Tome WA, Caine C, Corn B, Kanner A, Rowley H, Kundapur V, DeNittis A, Greenspoon JN et al (2014) Preservation of Memory With Conformal Avoidance of the Hippocampal Neural Stem-Cell Compartment During Whole-Brain Radiotherapy for Brain Metastases (RTOG 0933): A Phase II Multi-Institutional Trial. J Clin Oncol 32(34):3810-3816 